\title{
TANDEM-X DEM CALIBRATION AND PROCESSING EXPERIMENTS WITH E-SAR
}

\author{
J. Hueso González, M. Bachmann, R. Scheiber, C. Andres, G. Krieger \\ German Aerospace Center (DLR) - Microwaves and Radar Institute \\ Oberpfaffenhofen, D-82234 Wessling, Germany, \\ Tel.+49 8153283112, jaime.hueso@dlr.de
}

\begin{abstract}
The TanDEM-X mission has the goal to deliver a digital elevation model (DEM) that fulfils HRTI-3 quality requirements on a global scale. The interferometric height is determined by the phase difference between the two acquired images and the spatial geometry. Baseline errors intrinsic of the bi-static SAR configuration combined with errors and drifts of the radar instrument introduce phase inaccuracies in the interferogram. Therefore, an accurate calibration of the interferometric system parameters and independent height references are required. In order to validate the DEM calibration concept with real interferometric data, a measurement campaign was carried out with the experimental airborne radar system (E-SAR) of the German Aerospace Center (DLR) in Oberpfaffenhofen. This paper will present some of the various results from these interferometric experiments, stressing on the quality assessment of the ICESat GLAS14 elevation data, which will be a key aspect in a successful TanDEM-X DEM generation.
\end{abstract}

Index Terms - TanDEM-X, DEM calibration, ICESat height references, E-SAR, SRTM-C

\section{TANDEM-X DEM CALIBRATION}

The challenge of calibrating the TanDEM-X [1] DEM lies on the complexity of the system and the strong height accuracy requirements (Table 1), to be accomplished at global scale.

\begin{tabular}{|l|l|l|}
\hline Requirement & Specification & HRTI-3 \\
\hline $\begin{array}{l}\text { Absolute vertical accuracy } \\
\text { (global) }\end{array}$ & $90 \%$ linear error & $\mathbf{1 0 ~} \mathbf{~ m}$ \\
\hline $\begin{array}{l}\text { Relative vertical accuracy } \\
(100 \mathrm{~km} \times 100 \mathrm{~km})\end{array}$ & $\begin{array}{l}90 \% \text { linear point- } \\
\text { to-point error }\end{array}$ & $\begin{array}{l}\mathbf{2} \mathbf{~ m} \text { (slope }<20 \%) \\
4 \mathrm{~m}(\text { slope }>20 \%)\end{array}$ \\
\hline
\end{tabular}

Table 1 TanDEM-X DEM Specifications [2]

The bi-static interferogram, from which the DEM is derived, depends on the phase difference between the two SAR images and on the spatial geometry. The phase stability of the system is disturbed by instrument drifts and phase noises. The concept assumes that the satellites have already been internally calibrated for their mono-static operation and that the phase unwrapping errors have been eliminated during the interferometric processing. However, residual phase errors still remain. Additionally, baseline errors intrinsic of the bi-static SAR configuration, mainly due to small inaccuracies in the GPS antennas on board of the satellites, also introduce errors in the interferometric height. From a different point of view, the contributions to the residual height error can be classified depending on their temporal behaviour with respect to the datatake length. Hence, "slow-changing" errors will have a mainly systematic influence on the height realisation, whereas on the other hand there will be "fast" random errors due to coherence losses or phase noise.

Theory and simulations [3] foresee that the total error on an individual DEM acquisition (datatake) will exceed the height accuracy requirements. However, certain techniques can be applied to minimise the "slow-changing" systematic components of the residual height error, in order to keep the corrected DEM within the desired accuracy. Here is where the DEM Calibration Concept plays its important role, determining which and how these techniques will be applied.

Following the height accuracy requirements, two types of corrections are needed. Relative height corrections can be derived from concurring swath overlaps and crossing orbits in the data take scenario, by means of a block adjustment. On the other hand, absolute height calibration requires accurate height references, which have to be adequately distributed depending on the datatake adjustment scenario.

In the frame of the DEM calibration activities, simulations of the systematic residual height error of the TanDEM-X system for characteristic acquisition scenarios have been performed. These statistical analyses serve as input and basis for the TanDEM-X Mosaicking and Calibration Processor (MCP) [4], which will be the operational tool that will adjust the raw DEM by means of the most suitable least-squares block corrections [5]. Another important activity is the assessment of the accuracy and distribution of potential height references for TanDEM-X. The next section will describe this more in detail. 


\section{HEIGHT REFERENCES - ICESAT}

Height references, also called ground control points (GCPs), are required for the absolute calibration of the DEM. In TanDEM-X, they will be also applied to derive the functional models for the 2D correction functions of the MCP. To accomplish these goals, the GCPs need to have certain characteristics: controlled accuracy (better than HRTI-3) and global coverage (data available in all isolated land masses). In addition, local DEMs or references, usually more accurate and expensive than global sources, might be applied as a back-up solution, or when an improved DEM accuracy will be desired to fulfill a HRTI-4 DEM, a TanDEM-X secondary mission goal.

One of the most promising global height sources are the ICESat Space-borne Laser Altimeter (GLAS) data [6]. The laser footprint has a diameter of less than $70 \mathrm{~m}$ and spacing between samples of $170 \mathrm{~m}$ along track on the Earth's surface. They provide good absolute accuracy and a good global coverage for hooking in the DEM. The data structure provides, for each height sample, information related to the return pulse characteristics and the measurement conditions. The most important parameters are the number of Gaussian peaks needed to model the returned echo, the pulses' widths $(\sigma)$, the surface slope and roughness, the cloud layers and the surface type (land, water, ice or sea ice). Additionally, the vegetation coverage for each point is obtained from the MODIS database [7]. All these parameters allow establishing accuracy and selection criteria for the individual height samples. Therefore, ICESat will be the main height reference source for TanDEM-X.

All the height reference databases considered by this mission and their accuracy are summarized in Table 2.

\begin{tabular}{|c|c|c|c|}
\hline Function & GCP source & Coverage & Accuracy \\
\hline $\begin{array}{l}\text { PRELIMINARY } \\
\text { absolute cal. }\end{array}$ & SRTM & $\begin{array}{l}\text { C-Band: global } \\
\text { X-Band: global } \\
\text { with big gaps }\end{array}$ & $\sim 8.5 \mathrm{~m}$ \\
\hline $\begin{array}{l}\text { MAIN absolute } \\
\text { and relative cal. }\end{array}$ & ICESat & Global & \begin{tabular}{|l|}
$0.1 \mathrm{~m}-1 \mathrm{~m}$ \\
weather/terrain
\end{tabular} \\
\hline \multirow{2}{*}{$\begin{array}{c}\text { SECONDARY } \\
\text { absolute and } \\
\text { relative cal. }\end{array}$} & Ocean-land & Global; restrictions & $0.5 \mathrm{~m}$ \\
\hline & $\begin{array}{l}\text { Lidar/Airborne } \\
\text { DEM }\end{array}$ & Local & $0.1 \mathrm{~m}-0.5 \mathrm{~m}$ \\
\hline VALIDATION & GPS tracks & Selected regions & $0.5 \mathrm{~m}$ \\
\hline
\end{tabular}

Table 2 Height references and accuracies for TanDEM-X

A dedicated study of ICESat's height accuracy and data structure was performed, including a comparison between ICESat heights and several other DEMs over a test region. This will be described in the following sections.

\section{E-SAR EXPERIMENT}

In order to experimentally validate the efforts of the DEM calibration, an airborne SAR campaign was carried out with the experimental airborne radar system (E-SAR) of DLR. The current section describes the details of the experiment.

\subsection{E-SAR characteristics and accuracy}

The E-SAR system is a multi-frequency and multipolarisation SAR instrument, which is intensively used for preparation of future space-borne SAR missions. Among others, it allows interferometric measurements in single-pass and multiple-pass modes [8]. For the purpose of the TanDEM-X experiment, single-pass interferometric acquisitions were performed in X-band in full-baseline (ping-pong) mode. The height ambiguity for this mode varies as a function of incidence angle within a range of 25$40 \mathrm{~m}$. The relative height accuracy is in the order of 0.5$1.0 \mathrm{~m}$ and the retrieved absolute heights are usually accurate within $\pm 2 \mathrm{~m}$ in terrain with moderate topography.

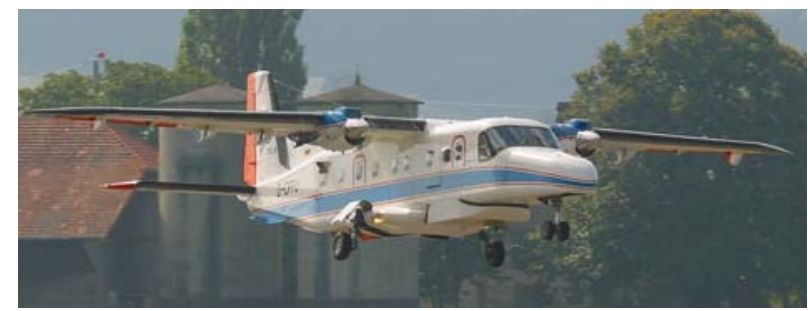

Figure 1 Do-228 aircraft carrying the E-SAR system.

\subsection{Test site and flight conditions}

The test region is located in the southeast of Munich, close to Miesbach (Fig. 2). The region contains several parallel and crossing ICESat GLAS14 tracks from the period autumn 2003 to spring 2007, which suits for the height comparison. Furthermore, the test region combines flat land in the north, forests and mountainous areas in the south, in order to identify dependencies from the terrain type.

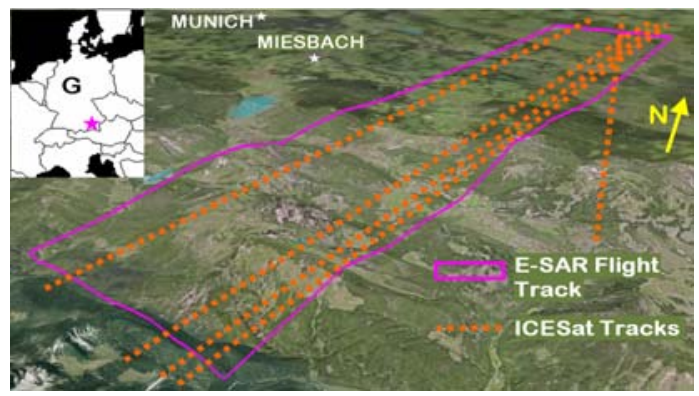

Figure 2 Miesbach test region (Google Earth).

Three parallel overlapping interferometric SAR images of $3 \mathrm{~km}$ width and $30 \mathrm{~km}$ length were acquired. Each stripe was acquired twice from different flight heights of $4.2 \mathrm{~km}$ and $3 \mathrm{~km}$, what results in different incidence angles.

\subsection{E-SAR processing}

For precise processing and in order to avoid iterative use of the generated E-SAR DEM, a Laser DEM (C Landesamt für Vermessung und Geoinformation) also over Miesbach has been used for facilitating topography dependent motion 
compensation. However, it has not been used for phase unwrapping or absolute height calibration. Instead two corner reflectors allowed compensating the absolute phase for a linear trend in range. The achieved accuracy compared to the Laser DEM is within specification. However, some forested areas have been identified with wrong phase unwrapping offset, and were excluded from subsequent analysis. The processed images are shown in Fig. 3.
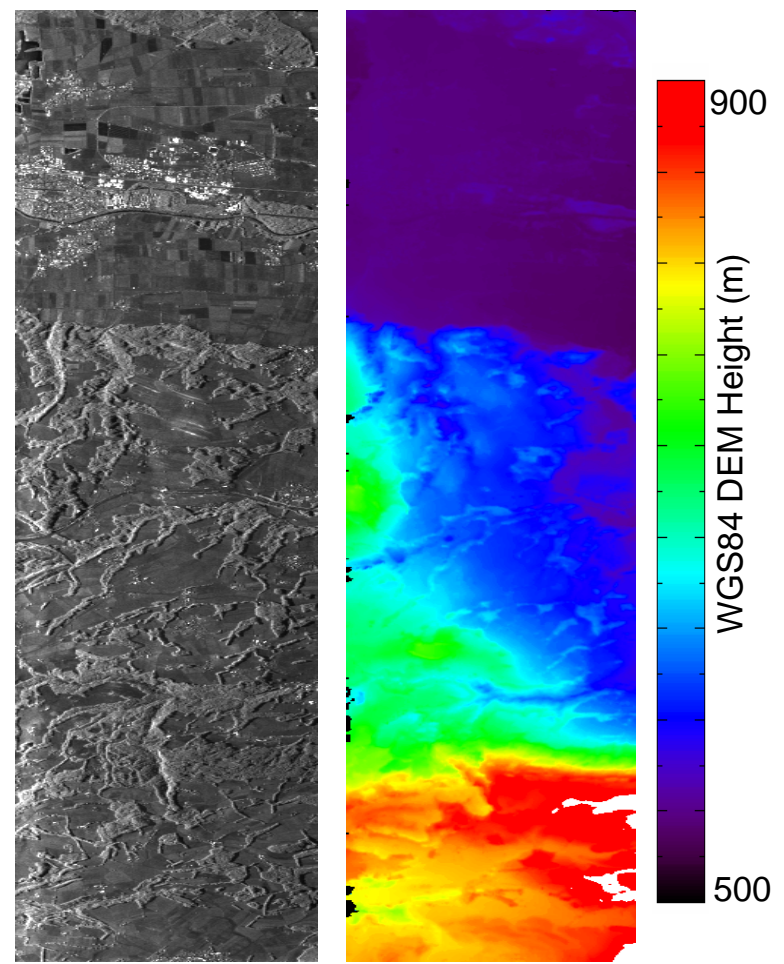

Figure 3 Miesbach E-SAR SAR image and DEM.

\section{ICESAT - DEM COMPARISON}

In order to select the best ICESat samples for comparison, preliminary criteria were adopted for these comparisons: echoes with only 1 Gaussian peak and a width $(\sigma)$ of less than 8 ns. The height differences corresponding to "good" points will be represented as orange stars, whereas the "filtered" points as blue crosses.

\subsection{Comparison ICESat - SRTM-C}

The SRTM-C band DEM has an almost global coverage, but less accuracy than ICESat, with $90 \mathrm{~m}$ resolution and $\pm 8.5 \mathrm{~m}$ vertical accuracy at $90 \%$ confidence [9]. However, it suits well for a preliminary consistency check of the height references in the Miesbach region.

Fig. 4 shows the differences between ICESat samples from the campaign of spring 2005 and SRTM-C DEM heights, plotted along latitude coordinates, together with the absolute SRTM-C heights. Some differences, mostly "filtered", but also "good" points, show surprisingly huge height errors of $300 \mathrm{~m}-2000 \mathrm{~m}$ with respect to the SRTM DEM.

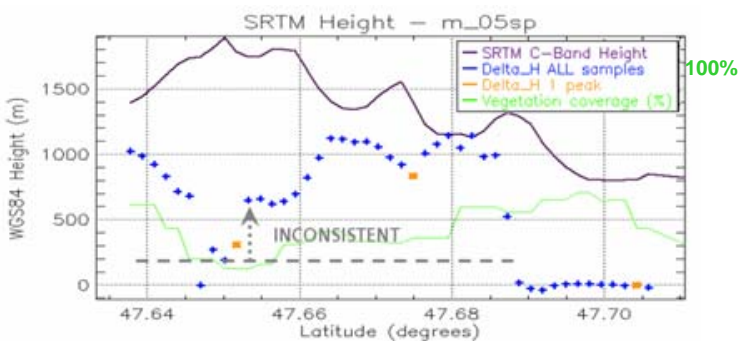

Figure 4 Example of inconsistent ICESat samples compared with SRTM C-Band data. Threshold $=200 \mathrm{~m}$.

The most probable cause is the presence of a thick cloud in these locations, where the laser pulses might have been reflected. However, no flag in the ICESat data structure warned about the presence of these clouds.

Therefore, it was decided to establish a threshold of $200 \mathrm{~m}$ in the difference with SRTM-C heights. In this way, all unreliable samples were withdrawn. Without taking into account these discarded samples, a statistic of the height differences over the whole test region could be done, and is included in Table 3.

\begin{tabular}{|c|c|c|c|c|}
\hline \multirow{2}{*}{\multicolumn{2}{|c|}{$\begin{array}{l}\text { Sta } \\
\text { Diff }\end{array}$}} & \multicolumn{3}{|c|}{ Filtering criteria } \\
\hline & & $\begin{array}{l}\text { All except } \\
\text { SRTM-C discard }\end{array}$ & $\begin{array}{l}\text { Basic criteria: } \\
1 \text { pk and } 8 \mathrm{~ns}\end{array}$ & $\begin{array}{l}\text { Extreme criteria: } \\
1 \mathrm{pk} \text { and } 3.2 \mathrm{~ns}\end{array}$ \\
\hline \multirow{3}{*}{$\begin{array}{l}\text { SRTM- } \\
\text { C Band }\end{array}$} & Mean & $0.24 \mathrm{~m}$ & $0.6 \mathrm{~m}$ & $1.7 \mathrm{~m}$ \\
\hline & StdDev $(1 \sigma)$ & $6.5 \mathrm{~m}$ & $3.2 \mathrm{~m}$ & $1.05 \mathrm{~m}$ \\
\hline & N. of points $/ \%$ & $500 / 97 \%$ & $150 / 29 \%$ & $21 / 4 \%$ \\
\hline \multirow{3}{*}{ E-SAR } & Mean & $-4.3 \mathrm{~m}$ & $-2.5 \mathrm{~m}$ & $-1.6 \mathrm{~m}$ \\
\hline & StdDev $(1 \sigma)$ & $6.7 \mathrm{~m}$ & $3.8 \mathrm{~m}$ & $1.1 \mathrm{~m}$ \\
\hline & N. of points $/ \%$ & $309 / 98 \%$ & $107 / 34 \%$ & $16 / 5 \%$ \\
\hline \multirow{3}{*}{ Laser } & Mean & $1.8 \mathrm{~m}$ & $-0.43 m$ & $-0.7 m$ \\
\hline & StdDev $(1 \sigma)$ & $6.5 \mathrm{~m}$ & $1.5 \mathrm{~m}$ & $0.17 \mathrm{~m}$ \\
\hline & N. of points $/ \%$ & $551 / 97 \%$ & $164 / 28 \%$ & $21 / 4 \%$ \\
\hline
\end{tabular}

Table 3 Statistics height differences ICESat - DEM

The mean of the error in for the SRTM-C DEM comparison is close to 0 , which proves that the ICESat data do not have significant trends or systematic errors. Applying the basic selection criteria, the standard deviation of the reliable differences is $\sigma=3.2 \mathrm{~m}$, even better than the expected SRTM-C accuracy. The statistic is slightly worse if all points are included. This speaks for the establishment of precise selection criteria.

\subsection{Comparison ICESat - E-SAR}

Fig. 5 shows one example of a height comparison between ICESat and E-SAR along an ICESat track.

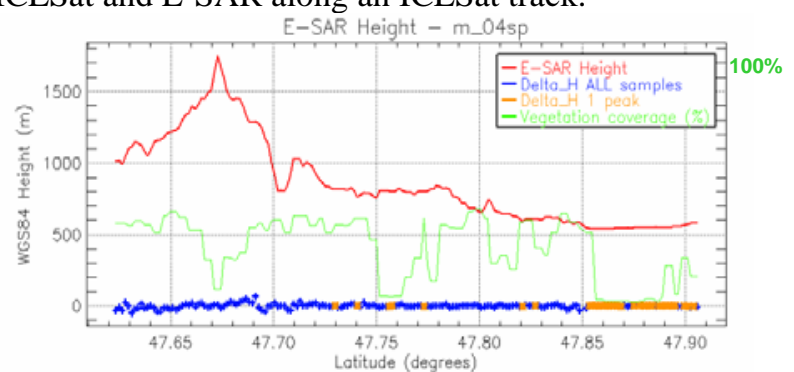

Figure 5 Height values of the E-SAR DEM and difference with ICESat samples. 
The plot indicates very clearly that flat zones contain most of the orange ICESat points. In the southern part of the ICESat track, where the Alps start, the mountainous terrain and the increase in vegetation coverage (see green MODIS curve) motivate more unreliable ICESat echoes.

The spread of the blue points seems to be higher than the one of the orange points, which speaks for the ICESat selection criteria.

The statistical analysis between ICESat and E-SAR differences over the whole test region is shown as well in Table 3. An offset appears for the E-SAR DEM and a higher standard deviation as expected, but comparable with SRTM. However, the spread can be reduced by sorting out the region where the phase unwrapping error was found. Furthermore, with more extreme selection criteria (Table 3), accuracies of almost $1 \mathrm{~m}$ are achieved, which agrees with the accuracy expectations of the E-SAR DEM.

\subsection{Comparison ICESat - Laser DEM}

With $0.5 \mathrm{~m}$ accuracy in flat areas, the laser DEM can give a better overview of the ICESat accuracy. The laser DEM and the comparison results are shown in Fig. 6.

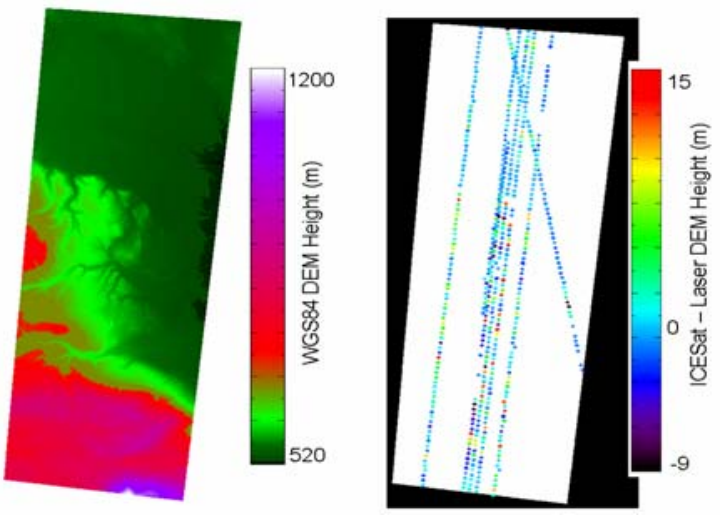

Figure 6 Laser DEM and difference with ICESat samples.

As pointed out in Table 3, the standard deviation is now smaller than in the other cases (almost reaching the maximum expected accuracy already for the basic selection criteria), having however a small offset of around $0.4 \mathrm{~m}$. The extreme selection criteria deliver an impressing accuracy of less than $0.2 \mathrm{~m}$.

\subsection{ICESat selection criteria}

Based on the results of Table 3, these would be the recommended selection criteria for ICESat samples in TanDEM-X:

1. Inconsistencies pre-selection with SRTM C-Band; threshold: $200 \mathrm{~m}$ difference

2. Basic selection criteria for normal DEM calibration activities: echoes with 1 peak and narrow $\sigma$ (8 ns threshold). It provides accuracies better than $1.5 \mathrm{~m}$ and availability of around $30 \%$ of the ICESat samples.
3. Extreme selection criteria for increased accuracy: echoes with 1 peak and very narrow $\sigma$ (3.2 ns threshold). It provides accuracies better than $0.2 \mathrm{~m}$, but only possible for areas with very high ICESat sample density.

4. Vegetation, terrain type, cloud layer parameters as a quality selection criteria (work ongoing)

\section{CONCLUSIONS AND OUTLOOK}

The E-SAR experiment assisted in the assessment of the accuracy of ICESat height data and in the establishment of selection criteria. The comparison with the different DEMs shows accuracies of between $1 \mathrm{~m}$ and $0.2 \mathrm{~m}$, after properly filtering the ICESat data, which implies that the best ICESat points have the same or better accuracy than the DEMs.

However, the statistical analysis for the extreme selection criteria may not be completely representative due to the reduced number of available samples.

Future work will continue in the direction of optimising the selection criteria for the height references in order to obtain maximum number of points and accuracy.

\section{ACKNOWLEDGEMENT}

We want to thank the E-SAR flight team for the successful acquisition of the Miesbach region, and also our colleagues B. Wessel, M. Huber, and M. Habermeyer (DLR-DFD) and F. Kurz (DLR-IMF) for preparing the Laser DEM from the "Landesvermessungsamt Bayern".

The TanDEM-X project is partly funded by the German Federal Ministry for Economics and Technology (Förderkennzeichen 50 EE 0601).

\section{REFERENCES}

[1] A. Moreira et al., "TanDEM-X: A TerraSAR-X Add-On Satellite for Single-Pass SAR Interferometry”, IGARSS, Anchorage, USA, 2004.

[2] "HRTI-3-DEM draft document”, NGA, MIL PRF 89048.

[3] G. Krieger et al., "A Satellite Formation for High Resolution SAR Interferometry”, IEEE TGRS, vol. 45, No. 11, pp. 3317-3341, Nov. 2007.

[4] B. Wessel et al., "Design of the DEM Mosaicking and Calibration Processor for TanDEM-X”, EUSAR, Friedrichshafen, Germany, 2008.

[5] E.M. Mikhail, “Observations and Least Squares”, IEP, New York, 1976.

[6] J. Abshire, et al. "Geoscience Laser Altimeter System (GLAS) on the ICESat Mission: On-orbit measurement performance”, Geophysical Research L., Vol. 32, 2005.

[7] MODIS data: http://glcf.umiacs.umd.edu/data/vcf/

[8] R. Scheiber, et al: "Advances in Airborne SAR Interferometry Using the Experimental SAR System of DLR”, Proc. EuRAD, Munich, 2007

[9] E. Rodriguez, et al. "An assessment of the SRTM topographic products”, Technical Report JPL D-31639, Jet Propulsion Laboratory, Pasadena, California. 